\title{
Two-year clinical outcomes of a multicenter randomized controlled trial comparing two interspinous spacers for treatment of moderate lumbar spinal stenosis
}

Vikas V Patel ${ }^{1}$, Peter G Whang ${ }^{2}$, Thomas R Haley ${ }^{3}$, W Daniel Bradley ${ }^{4}$, Pierce D Nunley ${ }^{5}$, Larry E Miller ${ }^{6,7}$, Jon E Block ${ }^{7 *}$ and Fred H Geisler ${ }^{8}$

\begin{abstract}
Background: Interspinous spacers are a minimally invasive surgical alternative for patients with lumbar spinal stenosis (LSS) unresponsive to conservative care. The purpose of this prospective, multicenter, randomized, controlled trial was to compare 2-year clinical outcomes in patients with moderate LSS treated with the Superion ${ }^{\oplus}$ (Experimental) or the X-Stop ${ }^{\oplus}$, a FDA-approved interspinous spacer (Control).

Methods: A total of 250 patients with moderate LSS unresponsive to conservative care were randomly allocated to treatment with the Experimental $(n=123)$ or Control $(n=127)$ interspinous spacer and followed through 2 years post-treatment. Complication data were available for all patients and patient-reported outcomes were available for 192 patients (101 Experimental, 91 Control) at 2 years.

Results: Zurich Claudication Questionnaire (ZCQ) Symptom Severity and Physical Function scores improved 34\% to $36 \%$ in both groups through 2 years (all $p<0.001$ ). Patient Satisfaction scores at 2 years were $1.8 \pm 0.9$ with Experimental and $1.6 \pm 0.8$ with Control. Axial pain decreased from $59 \pm 26 \mathrm{~mm}$ at baseline to $21 \pm 26 \mathrm{~mm}$ at 2 years with Experimental and from $55 \pm 26 \mathrm{~mm}$ to $21 \pm 25 \mathrm{~mm}$ with Control (both $p<0.001$ ). Extremity pain decreased from $67 \pm 24 \mathrm{~mm}$ to $14 \pm 22 \mathrm{~mm}$ at 2 years with Experimental and from $63 \pm 24 \mathrm{~mm}$ to $18 \pm 23 \mathrm{~mm}$ with Control (both $p<0.001)$. Back function assessed with the Oswestry Disability Index similarly improved with Experimental (37 $\pm 12 \%$ to $18 \pm 16 \%)$ and Control $(39 \pm 12 \%$ to $20 \pm 16 \%)$ (both $p<0.001)$. Freedom from reoperation at the index level was $84 \%$ for Experimental and $83 \%$ for Control (log-rank: $p=0.38$ ) at 2 years.

Conclusions: Both interspinous spacers effectively alleviated pain and improved back function to a similar degree through 2 years in patients with moderate LSS who were unresponsive to conservative care.
\end{abstract}

Trial registration: NCT00692276.

Keywords: Interspinous spacer, Lumbar spinal stenosis, Minimally invasive, Randomized controlled trial, Superion

\footnotetext{
* Correspondence: jonblock@jonblockgroup.com

${ }^{7}$ The Jon Block Group, 2210 Jackson Street, Suite 401, San Francisco, CA 94115, USA

Full list of author information is available at the end of the article
} 


\section{Background}

Lumbar spinal stenosis (LSS) is a common degenerative condition affecting the elderly that is characterized by narrowing of the spinal canal, lateral recesses, and/or neuroforamina that causes encroachment of surrounding soft tissue on the thecal sac and exiting nerve roots [1]. The natural history of LSS includes disease progression that may cause symptomatic neurogenic claudication, including pain in the buttocks or legs that is often exacerbated by standing, ambulating, and trunk extension. One of the classic features of LSS is pain alleviation with sitting or by standing/walking in a slightly flexed lumbar position.

The long-term effectiveness of nonsurgical LSS treatments such as activity modification, physical therapy, anti-inflammatory drugs, and epidural steroid injections is limited since these modalities have no impact on the rate of disease progression nor do they directly modify the diameter of the spinal canal [2-4]. In fact, 4 in 10 patients treated with conservative measures ultimately require decompressive surgery within 10 years due to symptom recurrence [5]. However, the potential for relief of claudication symptoms must be carefully balanced against the risks of treatment failure and surgical complications, particularly in the elderly [6]. There is a distinct treatment gap for patients with LSS who have unsuccessfully exhausted conservative treatments but whose symptom severity does not justify undergoing invasive decompression surgery.

Interspinous spacers are promising minimally invasive treatment alternatives for patients with persistent symptoms of LSS. Interspinous spacers are delivered via small, minimally traumatic incisions and implanted between contiguous spinous processes of a stenotic lumbar segment, with the goal of limiting back extension at the symptomatic level and alleviating neurogenic claudication symptoms. The purpose of this prospective, multicenter, randomized, controlled trial was to compare 2-year outcomes in patients treated with an investigational interspinous spacer or a Food and Drug Administration (FDA)-approved interspinous spacer.

\section{Methods}

\section{Ethics}

This clinical trial was conducted in strict accordance with a predefined protocol that was approved by all researchers and the institutional review board at each respective site [see Additional file 1]. This research followed the recommendations of the Helsinki Declaration and each patient provided written, informed consent before any studyrelated procedures were performed. This trial was prospectively registered at ClinicalTrials.gov (NCT00692276).

\section{Subjects}

Inclusion criteria for this trial included: (a) age $\geq 45$ years, (b) persistent leg, buttock, or groin pain, with or without back pain, that was relieved by lumbar flexion, (c) persistently symptomatic with unsuccessful response to at least 6 months of conservative treatment, (d) diagnosis of moderate LSS, defined as $25 \%$ to $50 \%$ reduction in central canal, lateral recess, or foraminal diameter compared to adjacent levels, and radiographic evidence of thecal sac compression and/or nerve root impingement by either osseous or non-osseous elements, and/or hypertrophic facets with canal encroachment, (e) Zurich Claudication Questionnaire Physical Function score $\geq 2.0$, (f) able to sit for 50 minutes without pain and to walk $\geq 50$ feet, and (g) able to provide voluntary informed consent and to comply with the study procedures. Exclusion criteria included: (a) LSS at three or more levels, (b) concomitant surgical procedure required, (c) grade II or greater spondylolisthesis, (d) unremitting back pain in any spinal position, (e) significant lumbar instability, defined as $\geq 3 \mathrm{~mm}$ translation or $\geq 5^{\circ}$ angulation, (f) active systemic disease that may affect the welfare of the patient, ( $\mathrm{g}$ ) vertebral osteoporosis or history of vertebral fracture, (h) body mass index $\geq 40 \mathrm{~kg} / \mathrm{m}^{2}$, (i) previous lumbar spine surgery, (j) pregnant or lactating female, and $(\mathrm{k})$ any disease or condition that, in the investigator's opinion, may affect subject safety or confound trial outcomes.

\section{Pre-treatment procedures}

Pre-treatment evaluations included a physical examination, medical history, and assessment for study eligibility based on the inclusion/exclusion criteria. Radiographic assessments included $\mathrm{x}$-rays (standing $\mathrm{A} / \mathrm{P}$, lateral lumbar, flexion/extension lateral lumbar) and magnetic resonance imaging or computed tomography of the lumbar spine. Self-reported measures included the Zurich Claudication Questionnaire (ZCQ) [7], a $100 \mathrm{~mm}$ visual analogue scale for extremity and axial pain severity, and the Oswestry Disability Index (ODI) (version 2) [8].

\section{Devices}

Patients were randomized to treatment with the Superion Interspinous Spacer (VertiFlex, Inc., San Clemente, CA, USA) or a Control spacer (X-Stop Interspinous Process Decompression System; Medtronic, Inc., Sunnyvale, CA, USA). The Superion device (Figure 1A and $1 \mathrm{~B}$ ) is an investigational device that is composed of titanium $6 \mathrm{AI}-4 \mathrm{~V}$ ELI alloy, a material that conforms to ASTM standards for surgical implants and commonly used in a variety of orthopedic applications [9]. Five device sizes are available, ranging from 8 to $16 \mathrm{~mm}$, with each size corresponding to the magnitude of desired distraction between the two spinous processes. This single-piece, self-expanding implant is delivered via minimally invasive access and deployed between the spinous processes of the involved vertebral levels. The Control spacer was approved for use in the United States by the FDA in November 2005 [10]. 

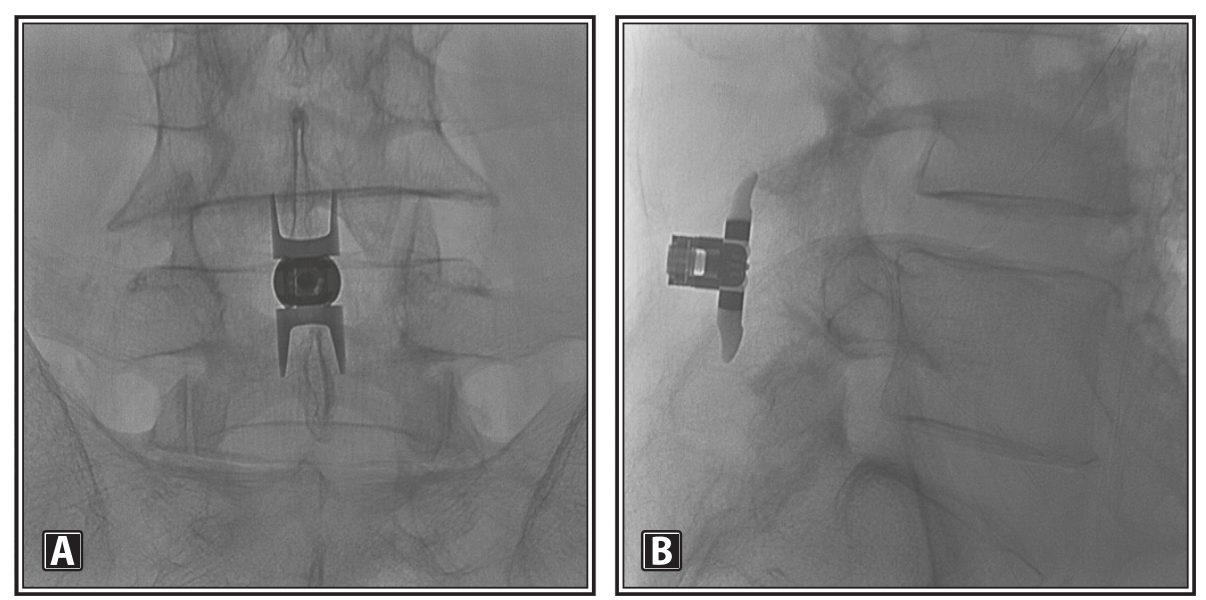

Figure 1 (A) A/P and (B) lateral radiographic image showing a properly placed Superion Interspinous Spacer.

Procedural details have been described elsewhere [11]. Interspinous spacers were implanted at $1(51 \%)$ or $2(49 \%)$ levels, with a comparable distribution between groups.

\section{Follow-up}

Subjects were followed through discharge and returned for visits at 6 weeks and 3, 6, 12, 18, and 24 months. Radiographic evaluations included standing A/P, lateral lumbar, and flexion/extension lateral lumbar x-rays. Postoperative care was prescribed according to individual subject needs and typically included medications, bracing, and/or physical therapy.

\section{Randomization and blinding}

Treatment groups were randomly assigned using computergenerated codes. Site personnel accessed a web-based system to obtain treatment assignment before each subject was enrolled. Treatments were not concealed to investigators, outcome assessors, or trial participants.

\section{Data analysis}

Data were analyzed using Predictive Analytics Software (v. 18, SPSS, Inc., Chicago, IL, USA). Continuous data were reported as mean $\pm \mathrm{SD}$ and categorical data were reported as frequencies and percentages. Longitudinal changes in clinical outcomes were assessed with two-way (time $\mathrm{x}$ treatment) repeated measures analysis of variance. Clinical success was defined as a $\geq 20 \mathrm{~mm}$ improvement in pain scores [12,13] and a $\geq 15$ percentage point improvement in ODI $[12,14]$. The Kaplan-Meier method and logrank tests were used to analyze freedom from interspinous process fracture and reoperation at the index level.

\section{Results}

\section{Subject characteristics}

A total of 250 patients were randomized to Experimental $(n=123)$ or Control $(n=127)$ and followed for a minimum of 2 years. All patients were included in safety analyses while $192(77 \%)$ patients had available 2-year patientreported outcomes; the remaining patients withdrew or were lost to follow-up. Mean patient age was 67 years, $60 \%$ were male, and mean body mass index was $30 \mathrm{~kg} / \mathrm{m}^{2}$. Grade I spondylolisthesis was identified in 34\% of Experimental patients and $28 \%$ of Control patients. Baseline patient characteristics were comparable between the groups.

\section{Zurich Claudication Questionnaire}

ZCQ symptom severity scores improved 36\% with Experimental and 34\% with Control through 2 years (both $\mathrm{p}<$ $0.001 ; p=0.60$ between groups) (Figure 2). Similar changes were noted in ZCQ physical function with improvements of 36\% with Experimental and 35\% with Control (both $\mathrm{p}<$ $0.001 ; \mathrm{p}=0.54$ between groups) (Figure 3 ). The mean ZCQ patient satisfaction score ranged from 1.6 to 1.9 in both groups at all follow-up visits (Figure 4).

\section{Axial pain severity}

Axial pain decreased $64 \%(59 \pm 26 \mathrm{~mm}$ to $21 \pm 26 \mathrm{~mm})$ at 2 years in the Experimental group and 62\% (55 $\pm 26 \mathrm{~mm}$ to $21 \pm 25 \mathrm{~mm}$ ) with Control (both $\mathrm{p}<0.001 ; \mathrm{p}=0.27$ between groups) (Figure 5). At 2 years, 66\% (67 of 101) of Experimental subjects and 62\% (56 of 91) of Control subjects achieved axial pain clinical success. A strong positive relationship was noted between pre-treatment axial pain severity and magnitude of improvement following interspinous spacer treatment in both groups (Experimental, $\mathrm{r}=0.67$; Control, $\mathrm{r}=0.62$; both $\mathrm{p}<0.001$ ).

\section{Extremity pain severity}

Extremity pain decreased $79 \%(67 \pm 24 \mathrm{~mm}$ to $14 \pm 22 \mathrm{~mm})$ at 2 years with Experimental and $71 \%(63 \pm 24 \mathrm{~mm}$ to $18 \pm$ $23 \mathrm{~mm}$ ) with Control (both $\mathrm{p}<0.001, \mathrm{p}=0.41$ between groups) (Figure 6). At 2 years, 79\% (80 of 101) of Experimental subjects and 75\% (68 of 91) of Control subjects 


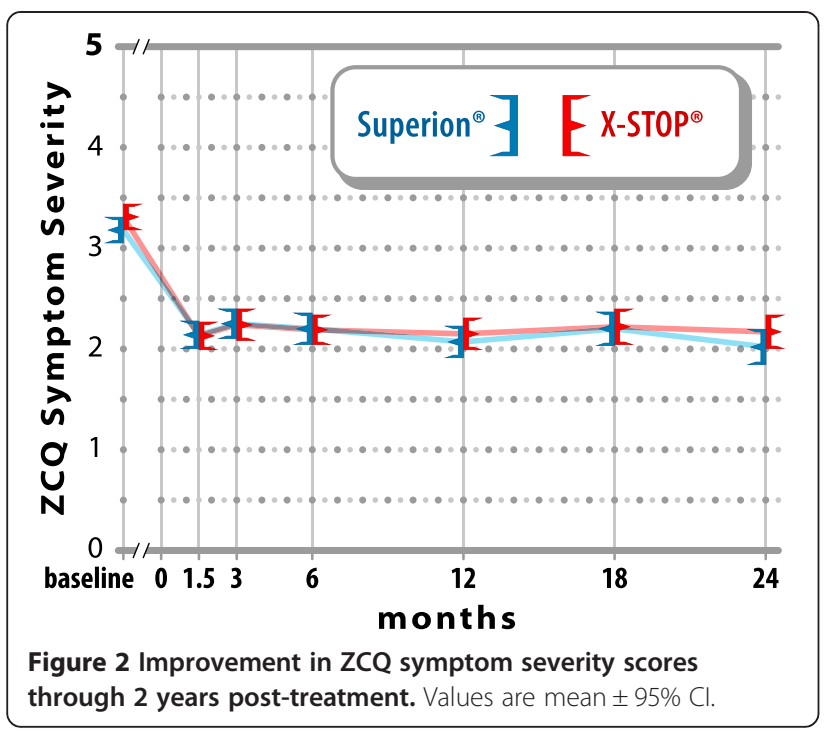

achieved extremity pain clinical success. A strong positive relationship was noted between pre-treatment extremity pain severity and magnitude of improvement following interspinous spacer treatment in both groups (Experimental, $\mathrm{r}=0.66$; Control, $\mathrm{r}=0.72$; both $\mathrm{p}<0.001$ ).

\section{Back-specific functional impairment}

Back function improved 51\% with Experimental (37 $\pm 12 \%$ to $18 \pm 16 \%)$ vs. $49 \%$ with Control $(39 \pm 12 \%$ to $20 \pm 16 \%)$ (both $\mathrm{p}<0.001, \mathrm{p}=0.87$ between groups) (Figure 7). At 2 years, 59\% (60 of 101) of Experimental subjects and 60\% (55 of 91) of Control subjects achieved back function clinical success. Weak relationships were noted between pre-treatment back function and magnitude of improvement following interspinous spacer treatment in either

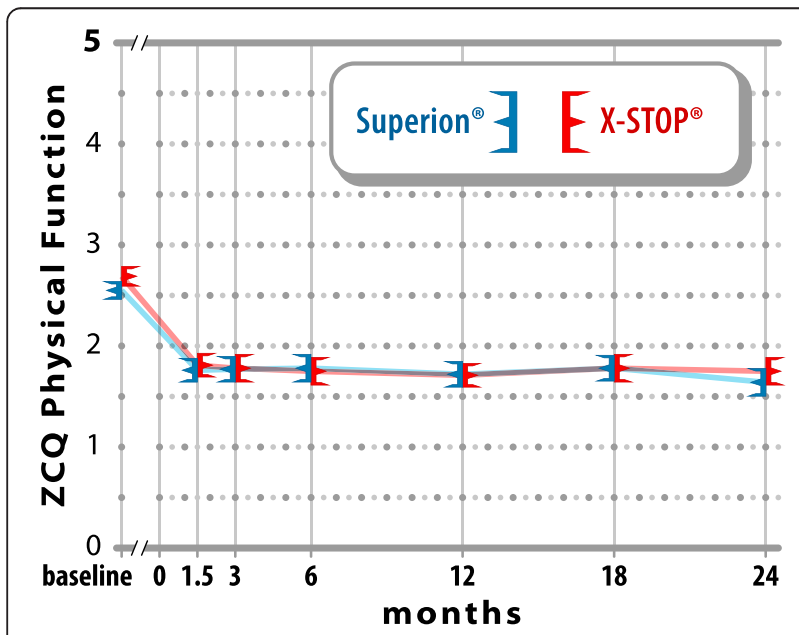

Figure $\mathbf{3}$ Improvement in ZCQ physical function scores through 2 years post-treatment. Values are mean $\pm 95 \% \mathrm{Cl}$.

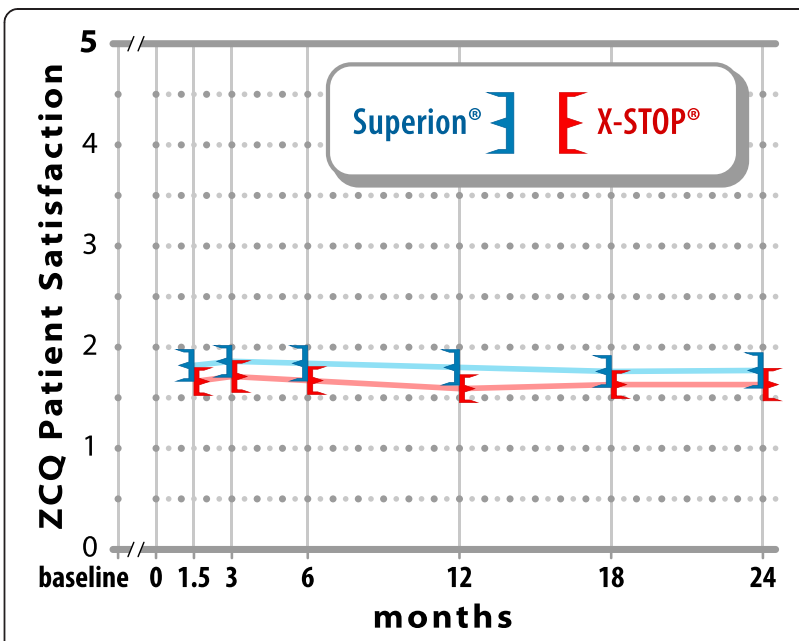

Figure 4 ZCQ patient satisfaction scores through 2 years post-treatment. Values are mean $\pm 95 \% \mathrm{Cl}$.

group (Experimental, $\mathrm{r}=0.21, \mathrm{p}=0.04$; Control, $\mathrm{r}=0.44$, $\mathrm{p}<0.001)$.

\section{Complications}

Postoperative deep wound infection was noted in 2 Control subjects, both successfully treated with incisional draining. The Kaplan-Meier estimate for freedom from a spinous process fracture was 93\% for Experimental and 96\% for Control (log-rank: $\mathrm{p}=0.38$ ) at 2 years. One Control patient underwent rhizotomy at 8 months post-implant. The Kaplan-Meier estimate for freedom from a reoperation at the index level was 84\% for Experimental and 83\% for Control (log-rank: $\mathrm{p}=0.93$ ) at 2 years. The timing of reoperations was 45\% in the first 6 months, 21\% between 6 and 12 months, and 33\% in the second year. The types of reoperations performed in each group are shown in Table 1.

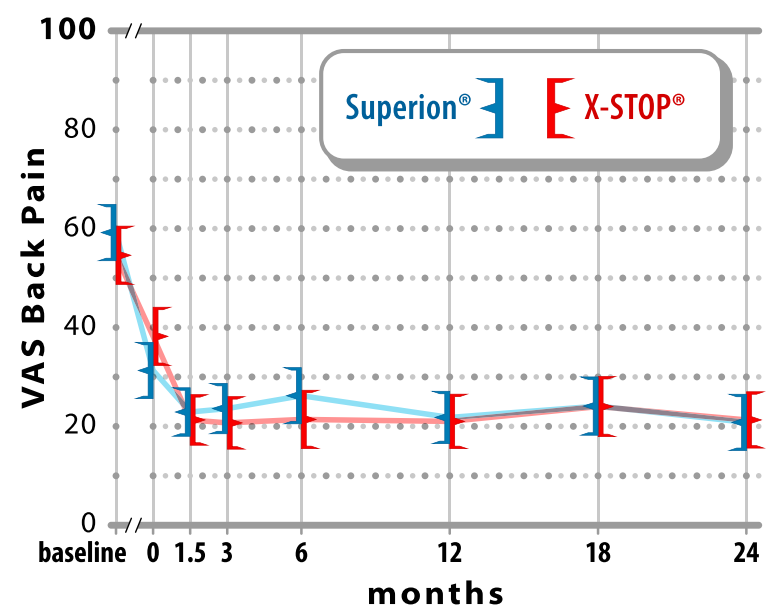

Figure $\mathbf{5}$ Improvement in axial pain severity through 2 years post-treatment. Values are mean $\pm 95 \% \mathrm{Cl} \mathrm{mm}$. 


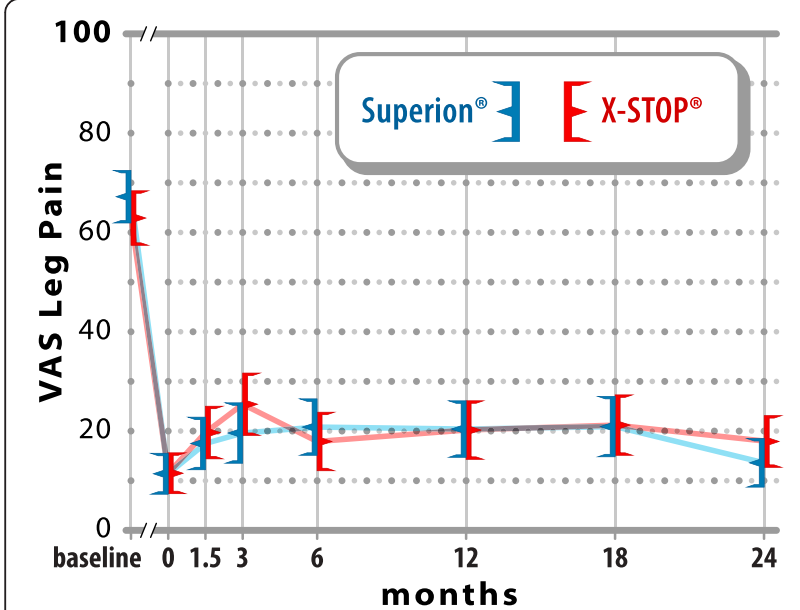

Figure 6 Improvement in extremity pain severity through 2 years post-treatment. Values are mean $\pm 95 \% \mathrm{Cl} \mathrm{mm}$.

\section{Subgroup analysis: Spondylolisthesis}

Among patients with preoperative grade I spondylolisthesis, 2-year outcomes were consistently better in the Experimental group although these differences were not statistically significant due to the limited sample size in the subgroup analysis (Table 2).

\section{Discussion}

Patients with moderate LSS remain an underserved population with no acceptably safe and effective treatment options. Interspinous spacers represent a viable treatment alternative for these patients that bridge the gap between conservative care and decompression surgery. The 2-year clinical outcomes of this trial demonstrate clinically meaningful improvements in back function, back pain, and leg pain in patients treated with the Experimental and Control interspinous spacers.

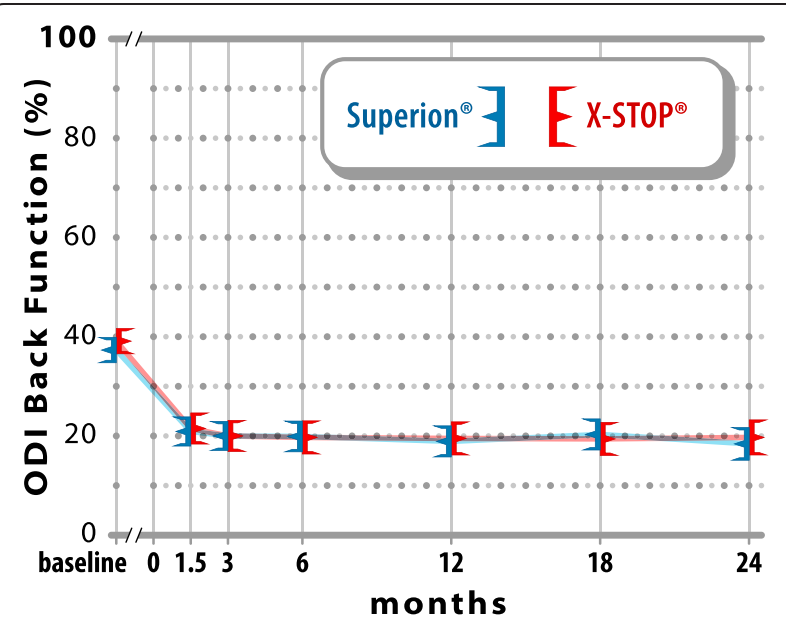

Figure 7 Improvement in back function through 2 years post-treatment. Values are mean $\pm 95 \% \mathrm{Cl}$.
Table 1 Reoperations through 2 years

\begin{tabular}{ccc}
\hline Variable & Experimental & Control \\
\hline Patients undergoing reoperation & $\mathbf{1 5}$ & $\mathbf{1 8}$ \\
-Explant & 12 & 14 \\
-Decompression surgery & 10 & 15 \\
-Fusion & 3 & 3 \\
-Discectomy & 1 & 2 \\
\hline
\end{tabular}

Sum of procedures is greater than sum of patients due to multiple procedures.

The mid-term effectiveness of the Experimental device is comparable to data reported in two previous studies. Bini and colleagues [15] reported 1-year outcomes of 52 patients treated with the Experimental device for moderate LSS. In that study, axial pain severity improved $49 \%$ ( $<<$ $0.001)$, extremity pain severity improved $53 \%(\mathrm{p}<0.001)$, and back function improved $64 \%(\mathrm{p}<0.001)$. Shabat and colleagues [16] treated 53 patients with the Experimental device for moderate LSS and reported clinical outcomes through 2 years. Similarly, axial pain severity improved $54 \%$, extremity pain severity improved $54 \%$, back function improved 50\%, ZCQ symptom severity improved 43\%, ZCQ physical function improved $44 \%$, and mean ZCQ patient satisfaction at 2 years was 1.9. Overall, the collective experience with the Experimental device to date suggests durable neurogenic claudication symptom amelioration. The effectiveness of the Experimental device in relieving symptoms of neurogenic claudication, the hallmark symptom of LSS, was particularly impressive with clinical success achieved in 8 in 10 patients in the current trial.

Data from the current study as well as from previous studies suggest that mid-term treatment effectiveness with interspinous spacers is comparable to that of open decompression surgery for moderate LSS [16-18]. The primary advantage of interspinous spacers is the minimally invasive approach, which is in stark contrast to the extensive resection of muscle, ligament, and bone that is typically required for traditional open decompression surgery. The specific procedural benefits of the Experimental procedure include a midline incision of only $1 \mathrm{~cm}$, minimal disruption

Table 2 Clinical outcomes at 2 years in patients with preoperative grade I spondylolisthesis

\begin{tabular}{|c|c|c|}
\hline Variable & Experimental & Control \\
\hline Axial pain success, $\%^{1}$ & 64.7 & 47.8 \\
\hline Extremity pain success, $\%^{1}$ & 76.5 & 69.6 \\
\hline Back function clinical success, $\%^{1}$ & 61.8 & 56.5 \\
\hline Freedom from spinous process fracture, $\%^{2}$ & 100 & 94.1 \\
\hline Freedom from reoperation, $\%^{2}$ & 85.0 & 76.5 \\
\hline \multicolumn{3}{|c|}{$\begin{array}{l}{ }^{1} \text { Among patients who completed } 2 \text { years follow-up, preoperative grade I } \\
\text { spondylolisthesis was identified in } 34(34 \%) \text { of } 101 \text { in the Experimental group } \\
\text { and } 23 \text { ( } 25 \%) \text { of } 91 \text { in the Control group. } \\
{ }^{2} \text { Among all patients included in the safety analyses, preoperative grade I } \\
\text { spondylolisthesis was identified in } 42(34 \%) \text { of } 123 \text { in the Experimental group } \\
\text { and } 36(28 \%) \text { of } 127 \text { in the Control group. }\end{array}$} \\
\hline
\end{tabular}


of the supraspinous ligament with preservation of the lamina and posterior ligamentous structures, short procedure time, and minimal blood loss. The lack of iatrogenic insult and associated complications combined with the postulated mechanism of action of immediate widening the spinal canal leads to rapid symptom improvement as evidenced by clinically meaningful neurogenic claudication symptom improvements at hospital discharge.

While the results of the present study are encouraging, the long-term durability of interspinous spacers is currently unknown and requires further study. Subjects in this trial will be followed through 5 years post-treatment. Although the clinical outcomes found in this study following treatment with the Experimental and Control spacers appear to be consistent with prior studies of open or minimally invasive decompression surgery, these decompression techniques were not directly compared with the Experimental device in this study, and thus comparisons of outcomes should be made with caution. With regard to patients with preoperative spondylolisthesis, long-term clinical outcomes with interspinous spacers were similar to those in patients without pre-existing spondylolisthesis. However, this study did not report the radiographic change in spondylolisthesis over time. Finally, we partly attribute the favorable results and low complication rates with both devices to the rigorous clinical and radiographic criteria employed in this clinical study. However, the generalizability of these outcomes to a real-world setting in patients with moderate LSS is unknown.

\section{Conclusions}

Both interspinous spacers effectively improved neurogenic claudication symptoms through 2 years in patients with moderate LSS. The clinical improvements observed in this trial were similar between the Experimental and Control interspinous spacers.

\section{Additional file}

Additional file 1: List of participating investigative sites.

\section{Competing interests}

Drs. Miller and Block are consultants to VertiFlex, Inc. (San Clemente, CA, USA).

\section{Authors' contributions}

All authors were involved in study design and development of this manuscript. All authors read and approved the final manuscript.

\section{Acknowledgements}

This trial is funded by VertiFlex, Inc. (San Clemente, CA, USA).

\section{Author details}

${ }^{1}$ University of Colorado Hospital, Denver, CO, USA. ${ }^{2}$ Yale Orthopaedics/Spine Service, New Haven, CT, USA. ${ }^{3}$ Performance Spine and Sports Physicians, P.C., Pottstown, PA, USA. ${ }^{4}$ Texas Back Institute, Denton, TX, USA. ${ }^{5}$ Spine Institute of Louisiana, Shreveport, LA, USA. ${ }^{6}$ Miller Scientific Consulting, Inc., Asheville, NC, USA. ${ }^{7}$ The Jon Block Group, 2210 Jackson Street, Suite 401, San Francisco,
CA 94115, USA. ${ }^{8}$ The Chicago Back Institute at Swedish Covenant Hospital, Chicago, IL, USA.

Received: 30 August 2013 Accepted: 1 July 2014

Published: 5 July 2014

\section{References}

1. Katz JN, Harris MB: Clinical practice. Lumbar spinal stenosis. N Engl J Med 2008, 358(8):818-825.

2. Markman JD, Gaud KG: Lumbar spinal stenosis in older adults: current understanding and future directions. Clin Geriatr Med 2008, 24(2):369-388. viii.

3. Deyo RA: Drug therapy for back pain. Which drugs help which patients? Spine (Phila Pa 1976) 1996, 21(24):2840-2849. discussion 2849-2850.

4. Cuckler JM, Bernini PA, Wiesel SW, Booth RE Jr, Rothman RH, Pickens GT: The use of epidural steroids in the treatment of lumbar radicular pain. A prospective, randomized, double-blind study. J Bone Joint Surg Am 1985, 67(1):63-66.

5. Atlas SJ, Keller RB, Wu YA, Deyo RA, Singer DE: Long-term outcomes of surgical and nonsurgical management of lumbar spinal stenosis: 8 to 10 year results from the maine lumbar spine study. Spine (Phila Pa 1976) 2005, 30(8):936-943.

6. Ciol MA, Deyo RA, Howell E, Kreif S: An assessment of surgery for spinal stenosis: time trends, geographic variations, complications, and reoperations. J Am Geriatr Soc 1996, 44(3):285-290.

7. Siddiqui M, Smith FW, Wardlaw D: One-year results of X Stop interspinous implant for the treatment of lumbar spinal stenosis. Spine (Phila Pa 1976) 2007, 32(12):1345-1348.

8. Fairbank JC, Pynsent PB: The Oswestry Disability Index. Spine (Phila Pa 1976) 2000, 25(22):2940-2952. discussion 2952

9. ASTM Standard F136-02a: Standard specification for wrought titanium-6 aluminum-4 vanadium ELI (extra low interstitial) alloy for surgical implant applications (UNS R56401). West Conshohocken, PA: ASTM International; 2002, DOl: 10.1520/F0136-02A, www.astm.org.

10. Chiu JC: Interspinous process decompression (IPD) system (X-STOP) for the treatment of lumbar spinal stenosis. Surg Technol Int 2006, 15:265-275.

11. Miller $L E$, Block JE: Interspinous spacer implant in patients with lumbar spinal stenosis: preliminary results of a multicenter, randomized, controlled trial. Pain Res Treat 2012, 2012:823509.

12. Ostelo RW, Deyo RA, Stratford P, Waddell G, Croft P, Von Korff M, Bouter LM, de Vet HC: Interpreting change scores for pain and functional status in low back pain: towards international consensus regarding minimal important change. Spine (Phila Pa 1976) 2008, 33(1):90-94.

13. Hagg $O$, Fritzell $P$, Nordwall A: The clinical importance of changes in outcome scores after treatment for chronic low back pain. Eur Spine $\mathrm{J}$ 2003, 12(1):12-20.

14. Zigler J, Delamarter R, Spivak JM, Linovitz RJ, Danielson GO 3rd, Haider TT, Cammisa F, Zuchermann J, Balderston R, Kitchel S, Foley K, Watkins R, Bradford D, Yue J, Yuan H, Herkowitz H, Geiger D, Bendo J, Peppers T, Sachs B, Girardi F, Kropf M, Goldstein J, et al: Results of the prospective, randomized, multicenter Food and Drug Administration investigational device exemption study of the ProDisc-L total disc replacement versus circumferential fusion for the treatment of 1-level degenerative disc disease. Spine (Phila Pa 1976) 2007, 32(11):1155-1162. discussion 1163.

15. Bini W, Miller LE, Block JE: Minimally invasive treatment of moderate lumbar spinal stenosis with the superion interspinous spacer: preliminary results. SAS J. In press.

16. Shabat $S$, Miller LE, Block JE, Gepstein R: Minimally invasive treatment of lumbar spinal stenosis with a novel interspinous spacer. Clin Interv Aging 2011, 6:227-233.

17. Postacchini R, Ferrari E, Cinotti G, Menchetti PP, Postacchini F: Aperius interspinous implant versus open surgical decompression in lumbar spinal stenosis. Spine J 2011, 11(10):933-939.

18. Bini W, Miller LE, Block JE: Minimally invasive treatment of moderate lumbar spinal stenosis with the superion interspinous spacer. Open Orthop J 2011, 5:361-367.

\section{doi:10.1186/1471-2474-15-221}

Cite this article as: Patel et al:: Two-year clinical outcomes of a multicenter randomized controlled trial comparing two interspinous spacers for treatment of moderate lumbar spinal stenosis. BMC Musculoskeletal Disorders 2014 15:221. 